\section{Homocysteine and cardiovascular risk}

\author{
A.F.G. Cicero • G. Derosa \\ A. Gaddi
}

Sir,

As researchers in the fields of metabolism, cardiovascular diseases and epidemiology, we wish to comment on the interesting paper of Ferraris et al. [1] that recently appeared in the Journal of Headache and Pain. We agree with the authors that the prevalence of cardiovascular disease risk factors in patients with migraine is high and that research into the etiopathogenetic similarities of different social diseases is important. However, we wish to highlight some doubts raised by Ferraris et al.'s study:

- The number of patients studied was a priori too small to detect a significant difference in the distribution of homocysteine levels that, in the normal population, range widely [2].

- Given the small sample size, we doubt that the data could have been normally distributed to justify the use of the $t$ test. The authors reported that patients with migraine have significantly lower plasma levels of folate than controls $(p=0.034)$; perhaps with a larger sample, this study would have led to more relevant differences in homocysteinemia [3].

- The study did not describe the patients' drug use or dietary habits. Both drug intake [4] and diet (especially alcohol consumption) greatly influence homocysteinemia and the homocysteinemic responses to methionine load [5].
- We understand that authors are not specialists in the field of cardiovascular disease risk factors. Still, we find it a little bit excessive to cite as risk factors HDLcholesterol and apolipoprotein A (they are clearly protective), as well as folate and vitamin B12.

- For the same reason, it is incorrect to state that reducing elevated plasma levels of homocysteine does not result in a reduction in cardiovascular risk [6].

- Finally, we question if the ethics committee of the authors' institution approved the methionine load experimentation in subjects not known to be basically hyperhomocysteinemic.

\section{References}

1. Ferraris E, Marzocchi N, Brovia D, Castellana CN, Pini LA (2003)

Homocysteine levels and cardiovascular disease in migraine with aura. $\mathbf{J}$ Headache Pain 4(2):62-66

2. Gaddi A, Cicero AFG, Nascetti S, Poli A, Inzitari D on behalf of the Italian Study Group for the Study of Dysmetabolic Diseases and Atherosclerosis (2003) Cerebrovascular disease in Italy and Europe: it is necessary to prevent a "pandemia". Gerontology 49(2):69-79

3. Mattson MP, Haberman F (2003) Folate and homocysteine metabolism: therapeutic targets in cardiovascular and neurodegenerative disorders. Curr Med Chem 10(19):1923-1929

4. Derosa G, Cicero AF, Ciccarelli L, Fogari R (2003) A randomized, double-blind, controlled, parallel-group comparison of perindopril and candesartan in hypertensive patients with type 2 diabetes mellitus. Clin Ther 25(7):2006-2021

5. Mennen LI, de Courcy GP, Guilland JC, Ducros V, Bertrais S, Nicolas JP,
Maurel M, Zarebska M, Favier A, Franchisseur C, Hereberg S, Galan P (2002) Homocysteine, cardiovascular disease risk factors, and habitual diet in the French Supplementation with Antioxidant Vitamins and Minerals Study. Am J Clin Nutr 76(6):1279-1289

6. Schnyder G, Roffi M, Flammer Y, Pin R, Eberli FR, Meier B, Turi ZG, Hess OM (2003) Effect of homocysteine-lowering therapy on restenosis after percutaneous coronary intervention for narrowings in small coronary arteries. Am J Cardiol

91(10):1265-1269

\author{
A.F.G. Cicero (更), A. Gaddi \\ G. Descovich Atherosclerosis Study \\ Center \\ D. Campanacci Department of Clinical \\ Medicine and Applied Biotechnology \\ Alma Mater Studiorum University of \\ Bologna, Bologna, Italy \\ e-mail: afgcicero@tiscali.it \\ Tel.: +39-051-6363652 \\ Fax: +39-051-390646
}

\section{G. Derosa}

Department of Internal Medicine and Therapeutics

University of Pavia, Pavia, Italy

\section{Reply from the author}

Sir,

The paper "Homocysteine levels and cardiovascular disease in migraine with aura" recently published by my colleagues and me [1] in The Journal of Headache and Pain was aimed to make only a small contribution to the worldwide discussion on the factors, including those regarding the cardiovascular system, that influence migraine with aura (MA). I would like to respond to Cicero and colleagues to explain the points that were not fully comprehensible in our article. 
- The small number of patients in the study was addressed in the paper, as we are well aware that the study cannot be considered to be exhaustive in investigating this problem. Cardiovascular risk is one of the main problems in preventive medicine; obviously, in order to provide medical doctors as well as patients with clear indications regarding healthcare choices, large population-based studies are needed. Recently, a number of large, well-conducted epidemiological studies and metaanalyses have come to conflicting conclusions regarding the pharmacological control of cardiovascular risk. In this light, our small study provided additional information without challenging any proven conclusion in the field of migraine pathogenesis.

- Alcohol consumption and diet of the patients were recorded as part of the general history. We did not discuss these issues in the paper because there were no significant deviations from the normal Italian diet.

- Obviously, HDL and apolipoprotein $\mathrm{A}$ are protective factors, as are folate and vitamin B12. Our discussion of these molecules was intended as a global evaluation of possible cardiovascular risk in patients with MA, to outline a possible influence of MA on factors routinely analyzed in the study of cardiovascular risk. The factors we studied were selected in order to compare our study group with those of other studies in the field of migraine [2-4], while other cardiovascular factors nonetheless relevant to MA pathogenesis, such as right-to-left shunt $[5,6]$, were not analyzed.

- Oral methionine load is a routine procedure at our institution for detecting patients with possible cardiovascular risk. All patients provide written informed consent before entering the study.

\section{References}

1. Ferraris E, Marzocchi N, Brovia D, Castellana CN, Pini LA (2003)

Homocysteine levels and cardiovascular disease in migraine with aura. $\mathrm{J}$ Headache Pain 4(2):62-66
2. Del Sette M, Angeli S, Ferriero G, Bruzzone GL, Finocchi C, Gandolfo G (1998) Migraine with aura and rightto-left shunt on transcranial Doppler: a case control study. Cerebrovasc Dis 8:327-330

3. Schlesinger I, Hering R (1997) Homocysteine levels in migraine patients. Cephalalgia 17:46

4. Merikangas KR, Fenton BT, Cheng SH, Stolar MJ, Risch N (1997) Association between migraine and stroke in a large-scale epidemiological study of the United States. Arch Neurol 54:362-368

5. Morandi E, Anzola GP, Angeli S, Melzi G, Onorato E (2003) Transcatheter closure of patent foramen ovale: a new migraine treatment? J Interv Cardiol 6:39-42

6. Del Sette M, Angeli S, Leandri M, Ferriero G, Bruzzone GL, Finocchi C, Gandolfo C (1998) Migraine with aura and right-to-left shunt on transcranial Doppler: a case-control study. Cerebrovasc Dis 6:327-330

L.A. Pini

Headache Study Center Policlinico

Via Del Pozzo 71

I-41100 Modena, Italy e-mail: pinila@unimo.it Tel.: +39-059-4224065 Fax: +39-059-4224069 